Canadian Journal of Fisheries and Aquatic Sciences Journal canadien des sciences halieutiques et aquatiques

\title{
Brook trout passage performance through culverts
}

\begin{tabular}{|r|l|}
\hline Journal: & Canadian Journal of Fisheries and Aquatic Sciences \\
\hline Manuscript ID & cjfas-2015-0089.R2 \\
\hline Manuscript Type: & Article \\
\hline Complete List of Authors: & $\begin{array}{l}\text { Goerig, Elsa; Institut National de la Recherche Scientifique, Centre Eau, } \\
\text { Terre \& Environnement } \\
\text { Castro-Santos, Theodore; USGS, S.O. Conte Anadromous Fish Research } \\
\text { Center } \\
\text { Bergeron, Normand; INRS - ETE , Centre Eau, Terre, et Environnement }\end{array}$ \\
\hline Keyword: & $\begin{array}{l}\text { FISHES < Organisms, HYDRAULICS < General, MOVEMENT < General, } \\
\text { Culvert, HABITAT < General }\end{array}$ \\
\hline &
\end{tabular}




$$
\text { Elsa Goerig }{ }^{13}
$$


$26{ }^{3}$ Groupe interuniversitaire de recherche en limnologie et en environnement aquatique (GRIL) 
Culverts can restrict access to habitat for stream-dwelling fishes. We used PIT telemetry

33 to quantify passage performance of $>1000$ wild brook trout attempting to pass 13 culverts of

34 Quebec under a range of hydraulic and environmental conditions. Several variables influenced

35 passage success, including complex interactions between physiology and behavior, hydraulics,

36 and structural characteristics. The probability of successful passage was greater through

37 corrugated metal culverts than through smooth ones, particularly among smaller fish. Trout

38 were also more likely to pass at warmer temperatures, but this effect diminished above $15^{\circ} \mathrm{C}$.

39 Passage was impeded at higher flows, through culverts with steep slopes and those with deep

40 downstream pools. This study provides insight on factors influencing brook trout capacity to

41 pass culverts as well as a model to estimate passage success under various conditions, with an

42 improved resolution and accuracy over existing approaches. It also presents methods that could

43 be used to investigate passage success of other species, with implications for connectivity of the

44 riverscape.

Keywords: fishes, hydraulics, movement, culvert, habitat

46 RÉSUMÉ

Les ponceaux peuvent limiter l'accès à l'habitat pour les espèces d'eau douce. Nous

48 avons utilisé la technologie des transpondeurs passifs intégrés (PIT-tags) afin de quantifier la

49 performance de passage de $>1000$ ombles de fontaine tentant de traverser 13 ponceaux du

50 Québec sous une gamme de conditions hydrauliques et environnementales. Plusieurs variables

51 influencent le succès de passage, incluant des interactions complexes entre la physiologie et le

52 comportement, l'hydraulique et les caractéristiques structurales des ponceaux. Les ponceaux de

53 métal ondulé augmentent la probabilité de passage et ce particulièrement pour les petits 
54 ombles. Les ombles sont plus susceptibles de franchir le ponceau lorsque la température de

55 l'eau s'élève mais cet effet diminue à partir de $15^{\circ} \mathrm{C}$. À l'opposé, le succès de passage est 56 moindre à des vitesses d'écoulement élevées, dans les ponceaux avec des pentes fortes ainsi

57 que dans ceux avec des fosses profondes à l'aval. Cette étude apporte de nouvelles 58 connaissances sur les facteurs influençant la capacité de l'omble de fontaine à franchir les 59 ponceaux ainsi qu'un modèle pour estimer le succès de passage sous des conditions variées, ceci 60 avec une résolution et une précision améliorée par rapport aux approches existantes. Elle 61 présente également des méthodes pouvant être utilisées pour étudier le succès de passage de 62 d'autres espèces, avec des implications pour la connectivité du paysage fluvial. Mots-clés : poissons, hydraulique, déplacement, ponceau, habitat INTRODUCTION Access to habitat is a fundamental metric of habitat quality. Fish need to move among

67 different habitats to optimally complete the stages of their life cycle; these include spawning, 68 feeding, rearing and seeking refuge from temporary harsh environmental conditions. Depending 69 on the heterogeneity and spatial arrangement of habitats, these may be located at variable 70 distances from each other. As a result, freedom of movement among these habitats plays a 71 critical role in fish life history and fitness (Fausch et al. 2002, Schlosser 1991).

72 Natural and human-derived elements of the riverscape such as falls, dams or road 73 crossings can reduce the degree of connectivity in river systems, affecting habitat availability for 74 fish and species dispersal. Moreover, at a population level, reduced fluvial connectivity causes 
75 partial or complete isolation of populations, a reduction in gene flow and an increased risk of 76 extirpation (Letcher et al. 2007, Whiteley et al. 2013, Wofford et al. 2005).

Culverts, one of the most widespread anthropogenic riverine features, can restrict 78 longitudinal movements of fish in small streams. Barriers to movements that result from 79 culverts can come in many forms. These include factors limiting the physiological ability of the 80 fish to enter the structure and swim upstream, but also factors influencing its behavior and level 81 of motivation to pass in an upstream or downstream direction (Gibson et al. 2005, Kemp and 82 Williams 2008). Because culvert hydraulics vary over time, passage performance is likewise variable. The 84 ability to cope with challenging hydraulic conditions is closely related to the species behavior 85 and swimming capacity. Individual variability in fish populations brings an additional level of 86 complexity and makes assessment of culvert passability particularly challenging (Kemp and

87 O'Hanley 2010). In the case of brook trout (Salvelinus fontinalis), a species displaying both 88 potamodromous and anadromous life histories, movements over long distances are not unusual 89 (Gowan and Fausch 1996, Kanno et al. 2014, Rodriguez 2002, Petty et al. 2012). This highlights 90 the potential negative impact of barriers. Previous studies addressing the issue of fish passage through culverts have used various

92 methods. These include the development of flowcharts or classification systems in order to 93 assess the degree of culvert passability and consequently the extent of watershed 94 fragmentation (Bourne et al. 2011, Coffman 2005, Poplar-Jeffers et al. 2009). These so-called 95 coarse filters mostly use static variables such as culvert length and slope, height of outlet drop 96 or presence of roughness elements in the structure. Although inexpensive to use, these 
97 methods have not been extensively validated with biological data and can lead to highly variable

98 results when compared to each other (Bourne et al. 2011).

Other methods have related the hydraulic conditions within the culvert with fish leaping and swimming performance data from laboratory settings in order to predict passage (Castro-

101 Santos 2005, Kondratieff and Myrick 2006, Neary 2012). The software FishXing (Furniss et al.

102 2006) uses this method to generate predictions of ascent distances and passage success. Some

103 authors have emphasized that FishXing overestimates the proportion of impassable culverts for 104 various species (Burford et al. 2009, Mahlum et al. 2013, Solcz 2007). This is partly because 105 these models are derived from swimming performance data obtained in controlled laboratory 106 environments that underestimated actual performance (Castro-Santos et al. 2013, Peake and 107 Farrell 2006, Tudorache et al. 2007).

Studies have examined the effects of culverts by comparing fish abundance

109 (MacPherson et al. 2012, Morita and Yamamoto 2002, Pépino et al. 2012) or genetic diversity

110 (Neville and Peterson 2014, Nislow et al. 2011, Torterotot et al. 2014) in streams with presence

111 of road crossings. These methods tell whether the culvert is passable but do not measure

112 passage performance itself. An experimental culvert test bed has otherwise been used to study

113 leaping capacity of juvenile fish (Mueller et al. 2008) as well as culvert passability (Peterson et al.

114 2013). In more natural conditions, fish movements in relation with the presence of culverts have

115 also been studied with telemetry or mark-recapture techniques (Burford et al. 2009, Coffman

116 2005, Mahlum et al. 2013). These studies focused on comparing movements between stream

117 reaches with culverts and natural reference reaches and were conducted on a single watershed.

118 Surprisingly, very few studies have sought to understand which variables are influencing 119 successful passage upstream, once the fish enter a culvert. Such an objective requires 
120 knowledge of individual passage attempts as well as current environmental and hydraulic

121 conditions. This knowledge is nevertheless essential to a thorough understanding of culvert

122 passability. Here we describe field observations and analysis of wild brook trout movements

123 through several culverts and model the effect of environmental, biological and hydraulic

124 variables on success.

125 METHODS

126 Study sites

Brook trout attempts and passage through culverts were recorded in field trials

128 conducted from 2009 to 2012 in nine culverts located in three watersheds of southern Quebec:

129 Sainte-Marguerite, Saint-Louis and Bécancour rivers (Table 1). Native brook trout is the

130 dominant species in the study areas, mostly exhibiting a potamodromous life history. Three

131 main criteria governed the choices of the study sites: 1) an outlet drop $<5 \mathrm{~cm}, 2$ ) absence of

132 substratum or roughness elements inside the culvert and 3) presence of high quality habitat

133 upstream. Culverts were randomly selected from among all sites $(n=15)$ that met these criteria.

134 The selected culverts comprised circular culverts made of metal, concrete or 135 polyethylene and one box culvert made of concrete. Metal culverts had annular or helical 136 (spiral) corrugations of 3-5 cm amplitude and $15 \mathrm{~cm}$ wavelength corresponding to a Manning's 137 roughness coefficient of 0.03 (Chow, 1959). Concrete or polyethylene culverts had no 138 corrugations and a coefficient of $\sim 0.010$ (Barfuss and Tullis, 1988). We will now refer to 139 corrugated metal culverts as "rough" and concrete or polyethylene culverts as "smooth". In case 140 of crossings with multiple pipes, each pipe was considered a separate site because their 141 respective characteristics (length, diameter or slope) were not identical. This increased the total 142 number of study sites to 13 . The length and slope of the culverts were measured with a 
143 theodolite TC705 (Leica Geosystems, Heerbrugg, Switzerland) by taking points at the upstream

144 and downstream extremities as well as at several locations along the culvert.

145 Hydraulic conditions

Distributions of flow velocity and water depth were quantified before each trial using an

147 electromagnetic (Marsh-McBirney Flow-Mate 2000) or propeller-type velocimeter (Swoffer,

148 model 3000 ) at lateral transects spaced $\sim 2 \mathrm{~m}$ along the culvert. At each transect, flow depth

149 and mean flow velocity were measured at $25 \%, 50 \%$ and $75 \%$ of the flow cross-section width

150 (Figure 2). These locations capture most of the range of velocities the fish are likely to encounter

151 while ascending the culvert. Depth was measured from the surface to the crest of the

152 corrugations and the corrugation's amplitude $(3-5 \mathrm{~cm})$ was considered as the boundary

153 roughness height. Velocity at each location was calculated by averaging instantaneous velocities

154 measured over a 30 second time interval, at a location corresponding to $40 \%$ of flow depth from

155 the bottom of the culvert. This location corresponds to the approximate mean flow velocity on

156 the vertical profile, according to the logarithmic distribution of velocities in turbulent flows in

157 open channels (Chow 1959, Von Karman 1931). Average flow depth and velocity for the culvert

158 were computed by averaging the mean values for each transect. Discharge was measured inside

159 the culvert by using cross-sectional area and velocities taken with the velocimeter.

161 culvert flow depth as

$162 \quad(1)$

$$
R e=U y / v
$$

$$
F r=\frac{U}{\sqrt{(g y)}}
$$


165 where $U$ is velocity $(\mathrm{cm} / \mathrm{s}), y$ is mean flow depth $(\mathrm{cm}), v$ is kinematic viscosity $\left(\mathrm{cm}^{2} \mathrm{~s}^{-1}\right)$ and $g$ is 166 acceleration due to gravity (cm/s) (Chow 1959, Vogel 1994).

167 using culvert dimensions and mean flow depth as

170

$$
R h=\frac{A}{P}
$$

171 where hydraulic radius $(\mathrm{Rh})$ is equal the flow area $(\mathrm{A})$ divided by the wetted perimeter $(\mathrm{P})$. For

172 rectangular culverts, flow area and wetted perimeter are estimated as

$$
\begin{aligned}
& A=\text { width } \times y \\
& P=\text { width }+2 y
\end{aligned}
$$

175 For circular culverts, flow area and wetted perimeter are estimated as

$$
A=r^{2}(\theta-\cos \theta \sin \theta)
$$

$$
P=2 r(\theta)
$$

178 where $r$ is the culvert radius and Theta $(\theta)$ is the characteristic angle (radians) estimated as

$$
\theta=6 \cos ^{-1}\left(1-\frac{y}{r}\right)
$$

180 Detailed information about culvert characteristics and hydraulics can be found in (Normann et 181 al. 1985).

\section{Fish collection and tagging}

Native brook trout were caught by electrofishing (Smith-Root backpack electrofisher, model 15-C, Vancouver WA, USA), 0-500 m upstream of the culverts, within $48 \mathrm{~h}$ of the trials.

185 When the densities upstream of the culvert were low, additional brook trout were caught 
downstream or in connected tributaries. Voltage and waveforms were adjusted to account for variation in water conductivity and to minimize risks of injury to the fish (DC varying width pulses, voltage range: $800-1100$, frequency: $45 / 60 \mathrm{~Hz}$, duty cycle range: $0.9-72 \%)$.

Fish were anesthetized with a solution of 1 part of clove oil for 10 parts of $95 \%$ ethanol diluted in water (0.8-1.2 $\mathrm{ml}$ of solution in $1400 \mathrm{ml}$ water; higher concentrations were used at colder water temperatures). Fish were then measured ( $\mathrm{FL}, \mathrm{mm}$ ), weighed (wet mass, $\mathrm{g}$ ) and surgically tagged with $23 \mathrm{~mm}$ PIT-tags (Texas Instrument, $23 \mathrm{~mm}$ in length, $3 \mathrm{~mm}$ in diameter; mass in air: $0.6 \mathrm{~g}$; tag-to-fish mass ratio: $0.42-8.22 \%$ ). Cyanoacrylate glue (Vetbond $3 \mathrm{M}$ ) was used to close the incision and fish were kept in holding pens placed in the stream for a recovery period ranging from 2 to $26 \mathrm{~h}$ (mean recovery time: $15 \mathrm{~h}$ ). All fish were inspected before release in order to detect any sign of injury or unusual behaviour. Such cases were rare and these fish were not used in the trials. When possible, three tagged fish were also kept in holding pens for the duration of the trial in order to control for tagging-induced mortality. Fish were cared for with conformity to the guidelines of the Canadian Council of Animal Care in science (CCPA) and the experimental protocol was reviewed and approved by the animal care review committee of the research institution.

\section{Study design}

Passage trials were conducted between June and October during continuous time periods ranging from 24 to $48 \mathrm{~h}$. Water temperature was recorded at a time interval of 15 minutes by a thermograph (Onset, HOBO 020-001-04) deployed in each stream near the culvert. Fish were released in a cage $(2 \mathrm{~m} \times 1.5 \mathrm{~m} \times 1.5 \mathrm{~m}$, Figure 1$)$ secured to the downstream extremity of the culvert and allowed to stage attempts at their own volition. A few large rocks were placed in the cage to provide rest areas. As an alternate treatment for some trials, fish were released in 
209 the pool downstream of the culvert, without the use of a cage, and the trial duration was

210 extended to $72 \mathrm{~h}$. When a trial was conducted on a culvert with multiple pipes, the cage was

211 fixed to a single pipe or, in case of an uncaged trial, the other pipes were blocked. From now on,

212 trials will be identified as "caged" or "uncaged" to refer to these two groups. When a trial was

213 conducted on a culvert with multiple pipes, the cage was fixed to a single pipe or, in case of an

214 uncaged trial, the other pipes were blocked. This ensured that fish could only access the pipe of

215 interest.

216 Instrumentation

Movements within the culvert were monitored with a passive integrated transponder

218 (PIT) telemetry system consisting of four antennas located inside the culvert at equal distance

219 from each other (Figure 1). The antennas were made of wire fixed to a rectangular plastic frame.

220 The dimensions vary with the culverts diameter, ranging from $0.45 \times 1 \mathrm{~m}$ to $0.45 \times 2 \mathrm{~m}$. The

221 antennas were located above the water surface to avoid flow disturbance, optimized for $23 \mathrm{~mm}$

222 PIT-tags and interfaced with a half-duplex PIT reader (Technologie Aquartis, control module

223 Quatro, multi-antennas system HDX-134.2 KHz) configured to charge and read tags at $10 \mathrm{~Hz}(2.5$

$224 \mathrm{~Hz}$ for each antenna). Horizontal and vertical detection ranges were recorded and adjusted if

225 necessary before each trial to ensure optimal system efficiency and cover the full water depth.

226 The vertical detection fields ranged from 15 to $60 \mathrm{~cm}$ from the plane of the antenna and

227 horizontal fields ranged from 5 to $15 \mathrm{~cm}$ upstream and downstream of the antennas. The reader

228 recorded tag number, antenna number and time to the nearest $1 \mathrm{~s}$ and stored this information

229 in a flash memory card. Detections within 1 second were grouped together, representing

230 discrete exposure to an antenna for a given fish. 
232 An attempt was defined as an upstream movement beginning at the furthest downstream

233 antenna (antenna 1) and was considered successful if fish reach the upstream-most antenna

234 (antenna 4) before the end of the trial. Conversely, it was considered a failed attempt if the fish

235 did not reach the fourth antenna during the trial time period and/or moved downstream. In

236 case a fish exited the culvert downstream and made multiple successive attempts, we applied a

237 threshold of 30 seconds between detections at the first antenna to differentiate among

238 attempts. Tagged fish returning from a previous trial and ascending the culvert were excluded

239 from the analysis. Detection efficiency of the PIT system was assessed by quantifying the

240 maximal antenna for every attempt and the detection by the previous antennas. This allowed us

241 to calculate a probability of successful detection for antennas 1, 2 and 3.

\section{Statistical analysis}

Logistic regression (Proc Logistic, SAS 9.3) was used to assess the effect of various

244 variables on the probability of passage success of caged fish. Fish that staged attempts were

245 counted. Their best attempt in terms of ascent distance was used to classify them as successful

246 or unsuccessful, depending on whether or not they reached the upstream end. The design

247 allowed fish to stage more than one attempt during a trial but only one observation per

248 attempting fish was used in the statistical analysis.

Culvert length, type and slope, average water temperature, mean flow velocity, mean

250 hydraulic radius, depth of downstream pool, fish length, spawning period and trial duration

251 were included as independent explanatory variables (Table 2). Discharge, Reynolds number and

252 mean flow depth were not used as explanatory variables due to strong correlation with

253 hydraulic radius ( $R>0.70$ in all cases). Culvert type was included as a categorical variable with 
254 value of 0 for rough and 1 for smooth culverts. Spawning period was also a categorical variable 255 with 0 and 1 being respectively more and less than two weeks and within two weeks from the 256 expected spawning time of the source population.

The set of candidate models $(n=208)$ included models comprising reasonable 258 combinations of the covariates. In order to minimize the number of candidate models, the set 259 was developed using the following criteria: 1) maximum of six main effects, 2) two-way 260 interactions only, 3) no interactions after five main effects and 4) use water temperature with its 261 quadratic term due to expected non-linearity in its effect on swimming performance in 262 sustained and prolonged mode (Beamish et al. 1978, Brett 1971, Lee et al. 2003). The duration 263 of the trial was included in all models with $=>$ three main effects to account for unequal trial 264 duration in the experimental design. Flow velocity, being expected to have an important effect 265 on passage success, was also included in all models with $\Rightarrow>$ three main effects. Culvert slope can 266 have an additional effect on performance. Because slope was correlated with flow velocity ( $R$ $267=0.54)$, it was only included in models that already included flow velocity. When slope and flow 268 velocity were together in a given model, a companion model comprising their interaction term 269 was also included. In this way, we explicitly tested for effects of slope other than those 270 associated with increased velocity.

271 Separate regression models were estimated using Standard International (SI) units and 272 normalized distance units. Normalization (division of distance metrics by body length) was done 273 to control for the fact that perception of distance and swimming ability is often correlated with 274 body size (Goolish 1991). Thus in the normalized regressions culvert length, depth of pool, and 275 hydraulic radius were converted to body lengths $(B L)$ and flow velocity to $B L / s$. One effect of this 
276 transformation was that conditions were no longer fixed at each culvert or trial, but instead 277 varied by individual.

278 During model selection, any model with a positive effect of culvert length or culvert 279 slope on passage success was rejected as it would not make sense biologically. For regressions in $280 \mathrm{SI}$ units as well as for those in normalized distance units, the best model was selected based on 281 minimum of Akaike information criterion (AIC), computed as

$$
A I C=-2 \log L+2 K
$$

283 where $L$ is the model's likelihood and $K$ the number of parameters

284 AIC allows the selection of the most parsimonious model providing a good fit to the data. Lower 285 AIC values indicate a better fit for the model. When comparing AIC values between the model 286 with minimum AIC and the others in the set, models with a delta AIC of less than 4 were 287 considered viable candidates for the best model (Burham and Anderson 2002).

The predictive power of the selected model was assessed on two datasets: caged fish 289 used to develop the model and a new dataset consisting of attempts and passage observations 290 for uncaged fish released freely in the stream. In both datasets, a subsample comprising fish 291 that reached at least the second antenna was also considered, in order to discriminate between 292 truly motivated individuals and those showing only exploratory behaviors. A method derived 293 from the leave-one-out principle (Proc logistic, Predprobs = X, SAS 9.3) was used to compute 294 cross-validated individual probability of passage for the caged fish. Tjur's $R^{2}$ and $c$ statistic, used 295 to assess the predictive power of the model, are measures of predictive power based on the 296 association between predicted probabilities and observed responses (Allison 2012, Hosmer et al. 297 2013). The $c$ statistic, equivalent to the area under the Receiver Operating Characteristic (ROC) 
298 curve, which is obtained by plotting the sensitivity (proportion of success correctly predicted) 299 against the inverse of the specificity (proportion of failures correctly predicted) for each 300 probability level. It ranges from 0.5 to 1 . Tjur's $R^{2}$ is a similar statistic useful to compare 301 predictive power between models or for a model applied to different datasets. It measures the 302 difference between the mean of the predicted values for observations with success = 1 and the 303 mean of the predicted values for observations with success $=0$. For both statistics, a value of 1 304 indicates a perfect fit between predicted and observed values.

\section{RESULTS}

\section{Trials conditions}

307 A total of 1090 fish (FL $85-240 \mathrm{~mm}$ ) was captured, pit-tagged and tested in 50 trials: 25 trials in 308 rough culverts and 25 in smooth ones. Each trial consisted of a group of 15 to 30 fish (mean: 22), 309 equally distributed in three size classes $(85-119 \mathrm{~mm} ; 119-149 \mathrm{~mm} ; \pm 150 \mathrm{~mm})$. A total of $833 \mathrm{fish}$ 310 were used in caged trials and 257 in uncaged trials. Trial durations ranged from 24 to $48 \mathrm{~h}$ (mean $311=48 ; \mathrm{SD}=14)$ for caged fish and 42 to $72 \mathrm{~h}$ (mean =55; SD=14) for uncaged fish. Trials were 312 conducted from mid-June to mid-October, at mean water temperatures between 3 to $18{ }^{\circ} \mathrm{C}$. 313 Mean flow velocity conditions ranged from 0.4 to $2 \mathrm{~m} / \mathrm{s}$ while the mean flow depth ranged from 3140.03 to $0.46 \mathrm{~m}$. For all trials, Reynold's numbers were well within the full turbulent flow range 315 (Chow 1959). Trials conducted in rough culverts were however characterized by higher 316 Reynold's numbers (median $=139400 ; 5^{\text {th }}-95^{\text {th }}$ pctl range $=54900-332600$ ) than those in smooth 317 culverts (median=55700; $5^{\text {th }}-95^{\text {th }}$ pctl range $=19600-177000$ ). A likely explanation for this is that 318 for a given velocity, depth was greater in rough culverts than in smooth ones. Froude number 319 was $<1$ for rough culverts and $\geq 1$ for smooth culverts, respectively indicating subcritical and 320 supercritical flows. 
Five mortalities were observed among the 77 control tagged fish held in holding pens

322 during the trials, for a survival of $94.5 \%$. The exact cause of death remained unknow but it could

323 have been induced by the tagging procedure. Eight additional fish (on 1098) died during the

324 surgery or the recovery period and were not used in the trials. The proportion of fish attempting

325 to pass the culverts differed greatly between caged and uncaged fish: $60 \%$ (496) of caged fish

326 staged at least one attempt while only $14 \%$ (36) of uncaged fish did $(P=<0.001, t$-test in SAS

327 9.3). Caged fish had only two choices: stay in the cage or stage attempts to pass the culvert, 328 which may have increased the proportion of attempters compared to free-ranging fish facing a

329 wider range of alternatives. For example, a proportion of uncaged fish could have moved 330 downstream and thus were not available to stage attempts. An additional antenna located 331 downstream of the culvert for uncaged trials would have allowed to know the number of fish 332 available. Unfortunately, this would have required a second PIT system at each site and would 333 have significantly increased the cost of the study. The higher density of individuals in the cage, 334 compared to the downstream pool during uncaged trials, may have also stimulated fish to move 335 upstream. Attempting fish had fork length located between 85 and $240 \mathrm{~mm}$ (median: $126 \mathrm{~mm}$; $33610^{\text {th }}-90^{\text {th }} \mathrm{pctl}$ range: $102-175 \mathrm{~mm}$ ). Passage success was higher for caged fish (logistic regression 337 in SAS 9.3, $P<0.01$ ), with $51 \%$ of attempters passing the culvert compared to $25 \%$ for uncaged 338 attempters. Successful fish had fork lengths ranging from 92 to $206 \mathrm{~mm}$ (median: $129 \mathrm{~mm} ; 10^{\text {th }}$ $33990^{\text {th }}$ pctl range: $\left.105-175 \mathrm{~mm}\right)$.

340 Detection efficiency by the PIT system was high in this study. The probability of 341 successful detection of a fish moving upstream was superior to $97 \%$ for antennas 1,2 and 3 . It 342 was not possible to quantify detection efficiency for antenna 4, although we can infer a high 343 value from the other antennas. When looking at returning fish moving downstream, we found 344 only two individuals with a maximal distance of ascent equivalent to antenna 3 and 
345 subsequently detected at antenna 4. These fish have exited the culvert without being detected 346 at antenna 4 but returned downstream later in the study.

\section{Model of passage success}

Among all 208 models tested, only one emerged as the most parsimonious and 349 providing a good fit to the data (Table 3 ). This best-fitting model included mean water 350 temperature, mean flow velocity, culvert slope, culvert type (rough vs smooth), depth of the 351 downstream pool and duration of the trial. This model is expressed as

$$
P(\text { success }=1)=\frac{e^{\beta_{0}+\beta_{1 x_{i 1}}+\beta_{2 x_{i 2}}+\cdots+\beta_{k x_{i k}}}}{1+e^{\beta_{0}+\beta_{1} x_{i 1}+\beta_{2 x_{i 2}}+\cdots+\beta_{k x_{i k}}}}
$$

where $\beta_{0}$ is the intercept and $\beta$ is the coefficient for each explanatory variable $\left(x_{i}\right)$ included in the

354 model

After careful observation of the diagnostic statistics, three observations had influence

356 over both model's fit and estimation of parameters. These observations, corresponding to fish

357 having failed to pass the culvert in relatively favorable conditions, were excluded from the 358 estimation of best model's parameters in order to get more reliable estimates. All culverts were 359 circular except one, a smooth box culvert with a low slope. In order to see if this culvert had a 360 particular effect on model selection, it was a-posteriori removed from the analysis. The results 361 remained unchanged and the same model was chosen as the best one. When modeling $P_{\text {success }}$ 362 with explanatory variables normalized to body length, the same model was selected as the best 363 one. However, the model in SI units had a reduced AIC with respect to the one in body length 
units (417.02 vs 437.48), thus maximizing the likelihood that this model is the best to 365 approximate reality given the data.

Initially, candidate models with six main effects were not allowed to have two-way

367 interactions. The best-fitting model includes culvert type and, based on field observations, we

368 hypothesized that the effect of roughness in culvert may be different depending on the fish

369 body size. Therefore, we included a-posteriori an interaction between culvert type and fish

370 length. This interaction further improved the model's AIC (389.17 vs 417.02) and was then kept

371 in the selected model.

Standardized coefficients $\left({ }^{x} \beta\right)$ measure the relative importance of the explanatory

373 variables, regardless of the metrics in which the variables have been measured (Table 4). Culvert

374 type had the greatest effect on success, followed by its interaction with fish length, culvert 375 slope, depth of downstream pool, water temperature, average water velocity and trial duration.

Body length had contradictory effects on fish passage performance, depending on type

377 of culvert ascended (Figure 3, panels A, B and C). Shorter fish performed better in rough culverts

378 while in smooth culverts performance increased with the size of the fish.

Slope had an evident negative impact on passage success (Figure 4, panels A, B and C), a

380 1-unit increase (1\%) in slope being associated with a $73 \%$ decrease in passage success (odds

381 ratio $=0.27$, Table 4). This effect was however less pronounced in rough culverts. Slope is the

382 measure of change in height per distance and so relates to the rate of working required to 383 elevate a mass. It also has important effects on hydraulics. Slope was correlated to flow velocity $384(R=0.54, p=<.001)$ with steep slope associated with faster flow velocities. Slope was also 385 correlated with hydraulic radius ( $R=0.22$ for rough and $\mathrm{R}=0.63$ for smooth culverts, $p=<.0001$ ), 
which was itself highly correlated with flow depth $(R=0.99, p=<.0001)$. Steeps slopes were therefore associated with shallow depths in smooth culverts but not necessarily in rough ones.

Depth of the staging area also affected $\mathrm{P}_{\text {success, }}$ with poorer success associated with deeper pools (Figure 5, panel A).

Passage success declined with increasing flow velocity, decreasing by $95 \%$ per $\mathrm{m} / \mathrm{s}$ (odds ratio $=0.05$, Table 4). Mean flow velocity had a negative effect on $P_{\text {success }}$ (Figure 5, panel B), and $\mathrm{mm})$. In a smooth culvert, $P_{\text {success }}$ falls under 0.5 at $\sim 0.8 \mathrm{~m} / \mathrm{s}$ while in a rough one it occurs at 1.5 $394 \mathrm{~m} / \mathrm{s}$.

The probability of success increased with water temperature towards an optimum around $14-15^{\circ} \mathrm{C}$, afterwards it decreased slowly until $18^{\circ}$ (Figure 5, panel C), which is the upper

397 limit of the range of tested temperatures.

Trout that were exposed to longer trials had greater opportunity to stage attempts. This

399 led to an increase of $8 \%$ per hour in the predicted odds of success (odds ratio $=1.08$, Table 4 ).

400 This effect is however limited to $48 \mathrm{~h}$, which is the longest trial duration for caged fish.

\section{Validation of model's predictive power}

The $c$-statistic and Tjur's $\mathrm{R}^{2}$ were high for the full training dataset and for the dataset 403 comprising only the uncaged fish. This was true both for the model with variables in SI units and 404 for the model with variables normalized to body lengths (Table 5). However, when only the fish 405 that swam further than the first antenna were considered, the predictive power decreased in 406 both datasets. 
When using predicted probabilities to assess passage success, a cut-off point is required

408 to switch from a prediction of failure to one of success. The ideal cut-off point is one maximizing

409 both sensitivity and specificity (Allison 2012, Hosmer et al. 2013). For our study, this cut-point

410 occurred at a probability level of 0.82 (Figure 6). The choice of the cut point value depends,

411 however, on the assessment of relative costs of the two types of errors in a given context:

412 predicting a passable culvert which in reality is not or predicting a barrier which is actually

413 passable.

414 DISCUSSION

This study describes passage performance of $>1000$ PIT-tagged wild brook trout in their

416 native streams through 13 culverts. The study design provided a unique ability to assess effects

417 of design, hydraulics and behavior on passage performance with some surprising results. These

418 highlight how successful passage is linked to several variables and is often the result of

419 interactions between behavioral and physiological aspects of fish swimming performance. Type

420 of culvert and its interaction with fish body length had the greatest effects on passage success.

421 These results offer improved tools for estimating habitat fragmentation for brook trout, for

422 prioritizing removal and retrofits of existing culverts, and for planning of future roadways and

423 stream crossings.

We used PIT telemetry to obtain these results, which is a cost-effective method that

425 allows continuous monitoring and recording of individual movement events. This contrasts with

426 indirect methods like mark-recapture or genetics tools that are useful to demonstrate that

427 movement has occurred (Neville and Peterson 2014, Whiteley et al. 2014) but have low

428 potential to quantify rate of movement for a population. Ultimately it is both the rate of 429 movement and passage success that determines connectivity. Thus the use of a direct method 
430 such as PIT telemetry or a combination of direct and indirect techniques is valuable to supply

431 the two different types of information. PIT telemetry can have effects on survival and swimming 432 performance, due to the surgery procedure (Bateman and Gresswell 2006, Gries and Letcher 433 2002, Ombredane et al. 1998) or the tag burden (Perry et al. 2013). $23 \mathrm{~mm}$ tags would still be 434 acceptable for salmonids of $\geq 80 \mathrm{~mm}$ (Bateman and Gresswell 2006). In the current study, some 435 fish had high tag-to-fish mass ratio, which can have negatively impacted their performance. 436 However, small fish showed good passage success in the culverts. Moreover, as the probability 437 of success was computed on attempting fish, mortalities during the trials would have reduced 438 the number of attempters but not the passage success itself. The probability of successful 439 detection at each PIT antenna was superior to $97 \%$ in this study. Some failed detections might 440 have happen at antennas 1 and 4, with effects such as underestimating the number of 441 attempters or the probability of successful passage. However, the high detection efficiency 442 makes these negligible effects with regards to the overall results.

Our results differ from existing literature where culvert passability has been mainly 444 related to the height of outlet drop (Kondratieff and Myrick 2006, Park et al. 2008) or the 445 average flow velocity inside the structure (Burford et al. 2009, Johnson et al. 2012, Warren and 446 Pardew 1998). In contrast our results suggest that culvert type was the most important factor 447 driving passability, with superior passage through rough culverts, especially for smaller fish. 
453 velocity zones. These can allow fish to achieve greater ascent distances by alternating between

454 resting and active swimming behaviors. Because of this, any model relating fish swimming 455 capacity to mean flow velocity $\left(\bar{U}_{f}\right)$ to predict passage success will underestimate passage 456 performance. Instead the ability to find and use these low velocity zones becomes a key element 457 for fish passage success.

The scaling of the roughness elements with the fish length might explain the increased 459 performance of small fish. The corrugation's characteristics in the studied rough culverts may 460 have allowed fish less than $15 \mathrm{~cm}$ to rest in the lee of a corrugation, where the flow velocity is 461 close to zero. Anecdotal observations of small fish resting in the lee of corrugations have been 462 made in the present study as well as in fishways and culverts (Belford and Gould 1989, Bunt et 463 al. 1999, Powers et al. 1997). This resting behavior might help them to recover from anaerobic 464 activity such as sprinting. Such resting behavior can improve passage success, but can also 465 reduce it, particularly if it reduces rates of upstream movement (Castro-Santos 2012, Wagner et 466 al. 2012). More work is needed to understand how hydraulic complexity influences swimming 467 ability and behaviors.

The effect of flow velocity is intuitive: as the mean flow velocity increases, fish fatigue 469 more rapidly and ascent distance decreases. Flow velocity is well-known to limit passage 470 performance (Haro et al. 2004, Peterson et al. 2013, Weaver 1963). In the current study, 471 however, flow velocity alone was not sufficient to adequately predict success.

473 swimming capacity is the dominant driver of success then one would expect success to decline 474 with culvert length (Castro-Santos et al. 2013, Haro et al. 2004). The absence of this variable in 475 the best model suggests that fatigue may not have been the primary cause of failure. A 
476 proportion of failed fish may have abandoned their ascents for reasons related to motivation.

477 Another explanation could be that, even in long culverts and fast flows, some successful fish 478 were able to avoid relying exclusively on their anaerobic metabolism, either by using the 479 corrugations to rest or low velocity zones to achieve greater ascent distances under aerobic 480 processes. It may also be important that our longest culverts all had relatively low slopes, and 481 there may have been some confounding interaction between these features. Finally, because 482 we quantified passage and not actual ascent distance it may be that the logistic regression 483 approach applied here lacked the power to accurately measure the effect of culvert length. 484 Therefore our results should not be interpreted as meaning that culvert length is unimportant, 485 but instead that other factors were also important and the combination of this, the study design 486 and the binary passage metric applied failed to detect an effect of culvert length.

We observed passage under a wide range of water temperature during the study and 488 found that $P_{\text {success }}$ is maximized at an average temperature of $\sim 15^{\circ} \mathrm{C}$. Interestingly, $14-15^{\circ} \mathrm{C}$ is the 489 average water temperature of the studied streams during the period between June and 490 September, when most of the trials were conducted. Aerobic performance of salmonids has 491 been observed to follows a bell-shaped curve (Brett 1971, Brett and Glass 1973), with an 492 optimum that approximates the average temperature of natal streams (Farrell 2007, Lee et al. 493 2003). For brook trout, maximal aerobic capacity occurs at $15^{\circ} \mathrm{C}$ (Tudorache et al. 2010). At low 494 temperature, the power production of red muscles is depressed. This requires early recruitment 495 (at lower swim speeds) of white muscle fibers that use anaerobic metabolism (Rome 1990). As 496 temperature approaches the optimum, aerobic function and power generation are maximized, 497 leading to a higher swimming performance (Brett 1971). Anaerobic metabolism is much less 498 affected by temperature (Beamish et al. 1978); fatigue occurs rapidly, reducing passage success 499 against fast flows in all but the shortest culverts (Haro et al. 2004; Castro-Santos et al. 2013). 
500 The critical flow velocity $\left(U_{\text {crit }}\right)$ at which fish will transition from one metabolism to the other 501 decreases at low temperatures, which should be considered in fish passage issues. 502 Temperatures are usually colder during spawning, when brook trout motivation to move is at its 503 highest level. It may then impede success at a critical stage of their life cycle. The current study 504 has been done both outside and during the spawning period and it would be worth exploring 505 further passage success with regards to cool water temperatures during spawning.

506 Culverts with steeper slopes are generally associated with poorer passage success due 507 to the positive relationship between slope and flow velocity (Belfort and Gould 1989, Coffman 508 2005, Powers and Orsborn 1985). However, independently of flow, slope may have effects on 509 passage performance. Indeed, it was an important predictor of passage success in the selected 510 model, even when flow velocity was already accounted for. One reason for this may be that that 511 steep slopes affect the relationship between buoyancy and weight forces acting on the fish. 512 These forces cancel each other at a zero slope and in static flow. This requires the fish to 513 generate more power in order to deliver the propulsive force necessary to overcome the slope 514 (Behlke 1991). Although this is an interesting concept, further work is needed to demonstrate its 515 occurrence on swimming fish and to assess the magnitude of the effect.

The effect of slope can also be related to its correlation with flow depth. The unequal

517 correlation between slope and flow depth in rough and smooth culverts may have implications 518 for passage success under a range of slopes and flow velocities. Our findings indicate that 519 success decreases with increase of slope, especially in smooth culverts (Figure 4). Even at high 520 flow $(1.7 \mathrm{~m} / \mathrm{s})$, passage success is possible in rough culverts of various slopes, perhaps due to 521 the fact that these structures retain deeper flow. A deeper flow inside the culvert has been 522 associated to greater swimming and leaping performance (Kondratieff and Myrick 2006, Powers 
523 and Orsborn 1985). Nevertheless, depth might not always be an important constraint to fish

524 upstream movements. In the present study, we observed fish ascending culverts at very shallow 525 depths $(<5 \mathrm{~cm})$, although it was against flow velocities $<1.2 \mathrm{~m} / \mathrm{s}$. Certainly, a deeper flow 526 means more space for the fish to swim, recruit various muscles groups and optimally use its fins

527 for propulsion and balance. Swimming near the surface generates waves and increase drag 528 compared to submerged swimming (Videler 1993). For a similar mean flow velocity ( $\left.\bar{U}_{f}\right)$, the 529 gradient of velocities in the cross-section will be less pronounced at a deeper flow, which means 530 that the size of the areas where $\mathrm{Uf}<$ or $>\overline{\mathrm{U}}_{\mathrm{f}}$ will be increased. A deeper flow may then allow the 531 fish to benefit from reduced velocity zones by swimming close to the culvert's bottom and walls 532 while simultaneously avoiding the surface. This might increase the probability of successful 533 passage at high flows.

Passage performance decreased with increasing depth of the downstream pool. This 535 variable can influence the perception by the fish of the oncoming flow as well as the level of 536 comfort in the cage. A deeper pool means more space and refugia for the fish in the cage.

537 Overall, caged fish staged more attempt than uncaged ones, which suggests that the behavior is 538 partly an escape response. The density of individuals in the cage was higher at shallow depths, 539 which may have increased their motivation to move upstream. Such pattern was observed for 540 Coho salmon in an experimental culvert (Johnson et al. 2012) and for alewives exiting pools in 541 fishways (Dominy 1973). The latter however considered the number of fish exiting rather than 542 the proportion exiting versus the number of fish available, which makes the results ambiguous. Longer trials improved passage success, probably because they offered more 544 opportunities for fish to ascend the culvert. More than half $(60 \%)$ of the caged fish staged 545 attempts during the trials and we modeled overall success, regardless of the number and timing 
546 of attempts. The proportion of attempters increases over time, perhaps influenced by variations

547 of flow, temperature or diurnal patterns. Moreover, the number of attempt per individual could

548 have an influence on performance. Castro-Santos $(2004,2006)$ demonstrated that fish staging

549 multiple attempts increase their ascent distance over time, each new attempt being an

550 opportunity for the fish to select an optimal swim speed and so maximize distance. In the event

551 the model is applied to predict passage of free-range fish, the trial duration should be the period

552 of time required for fish to pass the culvert or, from a management perspective, the acceptable

553 delay in upstream movement induced by the structure. Further analysis is needed to understand

554 better the effects of structural, biological and environmental variables on attempt rate of brook 555 trout.

Other factors have not been taken into account when modelling $P_{\text {success }}$. For instance, we

557 did not consider prior knowledge about the connectivity of sampled streams. Despite the fact

558 that most of the fish have been caught upstream of the studied culverts, some of them may

559 have interacted with the culvert before being tested and so acquired a certain learning of the

560 structure. Besides, fish had been collected from deep pools to shallow riffles and may have

561 developed various body morphologies and life histories in response to their habitat. When

562 modelling success, we did not consider the characteristics of the stream where the fish came

563 from. It is possible that individuals from fast-flowing or turbulent habitats had an increased

564 ability to face challenging areas such as culverts (Castro-Santos and Haro 2006, Clausen 1931).

565 Nonetheless, the fact that the proposed model has been developed with wild brook trout from

566 different populations, each of them occupying watersheds with distinct geomorphological and

567 ecological characteristics, increases the model's robustness and scope. This model was

568 developed with data integrating various behavioral responses to the presence of a culvert:

569 serious passage attempts as well as exploratory behaviors. Thus, it performed better at 
570 predicting outcomes for fish exhibiting different behaviors, which will likely be the case in the

571 field. The fact that the validation statistics remained high when the model was used to predict

572 success for the uncaged fish is interesting as such a model is intended to predict passage success

573 of wild, free-ranging fish.

574 This study provides new insight on underlying mechanisms of fish passage success 575 through culverts, interactions between physiological and behavioral components and the 576 beneficial effect of rough culverts. This means that replacing or relining corrugated metal 577 culverts with smooth ones, a practice that is gaining popularity to increase culvert's lifespan, will 578 have a detrimental effect on river connectivity. The increased ability of small fish to negotiate 579 rough culverts is also particularly important. It may indicate a unique adaptability to local 580 conditions in order to increase their capacity to move, which can have a high value from an 581 ecological point of view. In conclusion, basing predictions of culvert passability and design 582 criteria solely on fish physiological capacity can be misleading. The model developed here will 583 improve accuracy of passage predictions for brook trout ascending culverts under the range of 584 conditions described in Table 2. Although extensive work remains to be done, this is a first step 585 towards a more comprehensive approach to understand fish passage at road crossings.

587 Support for this research was provided by INRS-Centre Eau, Terre et Environnement, the GRIL, 588 the Ministère des Transports du Québec, the Fonds de la recherche forestière du Saguenay-Lac 589 Saint-Jean, and research scholarships to E.G from Natural Sciences and Engineering Research 590 Council of Canada and the Fonds de recherche Nature et Technologies du Québec. Any use of 591 trade, product, or firm names is for descriptive purposes only and does not imply endorsement 592 by the Canadian or U.S. Governments. We would like to thank the research assistants who 
593 helped conducting the field work: M.A. Pouliot, F. Bérubé, J.N. Bujold, J.B. Torterotot, S.

594 Dugdale, M. Fortin, C. Larouche, H. Bouchard, P. Marcotte, F. Pichon, J. Bédard and M.

595 Tisserand. We also extend special thanks to P. Johnston, M. Lafrance and D Boula for their

596 inputs and guidance throughout the study as well as to D. J. Alcott and B. H. Letcher for their

597 generous assistance with the manuscript. 
598

599

600 Institute.

601

602

603

604

605

606

607 Academic Press. pp. 101-187.

608

609

610

611

612 Belford, D.A., and Gould, W.R. 1989. An Evaluation of Trout Passage through Six Highway

613 Culverts in Montana. North American Journal of Fisheries Management 9(4): 437-445. doi:

614 10.1577/1548-8675(1989)009<0437:aeotpt>2.3.co;2.

615

616 Belfort, D.A., and Gould, W.R. 1989. An Evaluation of trout Passage through Six Highway 617 Culverts in Montana. North American Journal of Fisheries Management 9: 437-445.

618

619 Bourne, C., Kehler, D., Wiersma, Y., and Cote, D. 2011. Barriers to fish passage and barriers to 620 fish passage assessments: the impact of assessment methods and assumptions on barrier 
621 identification and quantification of watershed connectivity. Aquat. Ecol. 45(3): 389-403. doi: $622 \quad 10.1007 /$ s10452-011-9362-z.

623

624 Brett, J.R. 1971. Energetic Responses of Salmon to Temperature. A Study of Some Thermal 625 Relations in the Physiology and Freshwater Ecology of Sockeye Salmon (Oncorhynchus nerkd). 626 Am. Zool. 11(1): 99-113. doi: 10.1093/icb/11.1.99.

627 Brett, J.R., and Glass, N.R. 1973. Metabolic Rates and Critical Swimming Speeds of Sockeye 628 Salmon (Oncorhynchus nerka) in Relation to Size and Temperature. J. Fish. Res. Board Can. 629 30(3): 379-387. doi: doi:10.1139/f73-068.

630

631 Bunt, C.M., Katopodis, C., and McKinley, R.S. 1999. Attraction and Passage Efficiency of White 632 Suckers and Smallmouth Bass by Two Denil Fishways. North American Journal of Fisheries 633 Management 19(3): 793-803. doi: 10.1577/1548-8675(1999)019<0793:aapeow>2.0.co;2.

635 Burford, D.D., McMahon, T.E., Cahoon, J.E., and Blank, M. 2009. Assessment of trout passage 636 through culverts in a large Montana drainage during summer low flow. North American Journal 637 of Fisheries Management 29: 739-752. doi: 10.1577/M07-175.1.

639 Burham, K., and Anderson, D. 2002. Model Selection and Multivariate Inference: A Practical 640 Information-Theoretical Approach. Springer, New York.

642 Cahoon, J., MacMahon, T., and Stein, O. 2004. Fish passage in Montana Culverts; phase II643 Passage Goals. Montana State University. p. 26. 
645 Castro-Santos, T. 2004. Quantifying the combined effects of attempt rate and swimming 646 capacity on passage through velocity barriers. Can. J. Fish. Aquat. Sci. 61: 1602-1615. doi: doi: 647 10.1139/F04-094.

648

649 Castro-Santos, T. 2005. Optimal swim speeds for traversing velocity barriers: an analysis of 650 volitional high-speed swimming behavior of migratory fishes. J Exp Biol 208(3): 421-432. doi: $651 \quad 10.1242 /$ jeb.01380.

652 Castro-Santos, T. 2006. Modeling the effect of varying swim speeds on fish passage through 653 velocity barriers. Trans. Am. Fish. Soc. 135(5): 1230-1237. doi: 10.1577/t05-262.1.

654

655 Castro-Santos, T. 2012. Adaptive fishway design: a framework and rationale for effective 656 evaluations. In Monitoring, Funktionskontrollen und Qualitätssicherung an 657 Fischaufstiegsanlagen, 2. Kolloquium zur Herstellung der ökologischen Durchgängigkeit der 658 Bundeswasserstraßen. Koblenz, Germany, pp. 76-89.

659

660 Castro-Santos, T., and Haro, A. 2006. Biomechanics and fisheries conservation. In Fish 661 Physiology, volume 23: Fish Biomechanics. Edited by R.E. Shadwick and G.V. Lauder. Academic 662 Press, New York. pp. 469-523.

663

664 Castro-Santos, T., Sanz-Ronda, F.J., and Ruiz-Legazpi, J. 2013. Breaking the speed limit 665 comparative sprinting performance of brook trout (Salvelinus fontinalis) and brown trout (Salmo 666 trutta). Can. J. Fish. Aquat. Sci. 70(2): 280-293. doi: doi:10.1139/cjfas-2012-0186.

667

668 Chow, V.T. 1959. Open-channel hydraulics. McGraw Hill Book Company. 
669 Clausen, R.G. 1931. Orientation in Fresh Water Fishes. Ecology 12(3): 541-546. doi: $670 \quad 10.2307 / 1928999$.

671

672 Coffman, J.S. 2005. Evaluation of a predictive model for upstream fish passage through culverts, 673 Biology, James Madison University.

674

675 Dominy, C.L. 1973. Effect of Entrance-Pool Weir Elevation and Fish Density on Passage of 676 Alewives (Alosa pseudoharengus) in a Pool and Weir Fishway. Trans. Am. Fish. Soc. 102(2): 398677 404. doi: 10.1577/1548-8659(1973)102<398:eoewea>2.0.co;2.

678

679 Ead, S.A., Rajaratnam, N., Katopodis, C., and Ade, F. 2000. Turbulent open-channel flow in 680 circular corrugated culverts. Journal of Hydraulic Engineering-Asce 126(10): 750-757.Available 681 from $<$ Go to $|S|>: / / 000089579200004$.

682

683 Farrell, A.P. 2007. Cardiorespiratory performance during prolonged swimming tests with 684 salmonids: a perspective on temperature effects and potential analytical pitfalls. Philosophical 685 Transactions of the Royal Society B: Biological Sciences 362(1487): 2017-2030. doi: $686 \quad 10.1098 /$ rstb.2007.2111.

687

688 Fausch, K.D., Torgersen, C.E., Baxter, C.V., and Li, H.W. 2002. Landscapes to Riverscapes: 689 Bridging the Gap between Research and Conservation of Stream Fishes: A Continuous View of 690 the River is Needed to Understand How Processes Interacting among Scales Set the Context for 691 Stream Fishes and Their Habitat. BioScience 52(6): 483-498. doi: 10.1641/0006692 3568(2002)052[0483:Itrbtg]2.0.co;2. 
694 Gibson, R.J., Haedrich, R.L., and Wernerheim, C.M. 2005. Loss of Fish Habitat as a Consequence 695 of Inappropriately Constructed stream Crossings. Fisheries 30(1): 10-17.

696

697 Goolish, E.M. 1991. Aerobic and Anaerobic scaling in Fish. Biological Reviews 66(1): 33-56. doi:

698 10.1111/j.1469-185X.1991.tb01134.x.

699

700 Gowan, C., and Fausch, K.D. 1996. Mobile brook trout in two high elevation Colorado streams:

701 re-evaluating the concept of restricted movements. Can. J. Fish. Aquat. Sci. 53: 1370-1381.

702

703 Gries, G., and Letcher, B.H. 2002. Tag retention and survival of age-0 atlantic salmon following 704 surgical implantation with passive integrated transponder tags. North American Journal of 705 Fisheries Management 22(1): 219-222. doi: 10.1023/a:1017022026937.

706

707 Haro, A., Castro-Santos, T., Noreika, J., and Odeh, M. 2004. Swimming performance of upstream 708 migrant fishes in open-channel flow: a new approach to predicting passage through velocity 709 barriers. Can. J. Fish. Aquat. Sci. 61: 1590-1601.

710

711 Hosmer, D.W., Lemeshow, S., and Sturdivant, R.X. 2013. Applied logistic regression. John Wiley 712 \& Sons.

713

714 Johnson, G.E., Pearson, W.H., Southard, S.L., and Mueller, R.P. 2012. Upstream Movement of 715 Juvenile Coho Salmon in Relation to Environmental Conditions in a Culvert Test Bed. Trans. Am.

716 Fish. Soc. 141(6): 1520-1531. doi: 10.1080/00028487.2012.699013. 
718 Kanno, Y., Letcher, B.H., Coombs, J.A., Nislow, K.H., and Whiteley, A.R. 2014. Linking movement 719 and reproductive history of brook trout to assess habitat connectivity in a heterogeneous 720 stream network. Freshwater Biol. 59(1): 142-154.

721

722 Kemp, P.S., and Williams, J.G. 2008. Response of migrating Chinook salmon (Oncorhynchus 723 tshawytscha) smolts to in-stream structure associated with culverts. River Research and 724 Applications 24(5): 571-579. doi: 10.1002/rra.1140.

725

726 Kemp, P.S., and O'Hanley, J.R. 2010. Procedures for evaluating and prioritising the removal of 727 fish passage barriers: a synthesis. Blackwell Publishing Ltd. pp. 297-322.

728 Kondratieff, M.C., and Myrick, C.A. 2006. How High Can Brook Trout Jump? A Laboratory 729 Evaluation of Brook Trout Jumping Performance. Trans. Am. Fish. Soc. 135(2): 361-370. doi: $730 \quad 10.1577 / \mathrm{t} 04-210.1$.

731

732 Lee, C.G., Farrell, A.P., Lotto, A., MacNutt, M.J., Hinch, S.G., and Healey, M.C. 2003. The effect of 733 temperature on swimming performance and oxygen consumption in adult sockeye 734 (Oncorhynchus nerka) and coho (O. kisutch) salmon stocks. J. Exp. Biol. 206(18): 3239-3251. 735 doi: 10.1242/jeb.00547.

736

737 Letcher, B.H., Nislow, K.H., Coombs, J.A., O'Donnell, M.J., and Dubreuil, T.L. 2007. Population 738 Response to Habitat Fragmentation in a Stream-Dwelling Brook Trout Population. PLoS ONE 739 2(11): e1139. doi: 10.1371/journal.pone.0001139.

740 
741 MacPherson, L.M., Sullivan, M.G., Foote, A.L., and Stevens, C.E. 2012. Effects of Culverts on 742 Stream Fish Assemblages in the Alberta Foothills. North American Journal of Fisheries 743 Management 32(3): 480-490. doi: 10.1080/02755947.2012.686004.

744

745 Mahlum, S., Cote, D., Wiersma, Y.F., Kehler, D., and Clarke, K.D. 2013. Evaluating the Barrier 746 Assessment Technique Derived from FishXing Software and the Upstream Movement of Brook 747 Trout through Road Culverts. Trans. Am. Fish. Soc. 143(1): 39-48. doi: $748 \quad 10.1080 / 00028487.2013 .825641$.

749

750 Morita, K., and Yamamoto, S. 2002. Effects of Habitat Fragmentation by Damming on the 751 Persistence of Stream-Dwelling Charr Populations. The Journal of the Society for Conservation 752 Biology 16(5): 1318-1323. doi: 10.1046/j.1523-1739.2002.01476.x.

753

754 Mueller, R.P., Southard, S.S., May, C.W., Pearson, W.H., and Cullinan, V.I. 2008. Juvenile coho 755 salmon leaping ability and behavior in an experimental culvert test bed. Trans. Am. Fish. Soc. 756 137(4): 941-950. doi: 10.1577/t06-244.1.

757

758 Neary, V.S. 2012. Binary Fish Passage Models for Uniform and Nonuniforms Flows. River 759 Research and Applications 28(4): 418-428. doi: 10.1002/rra.1564.

760

761 Neville, H.M., and Peterson, D.L. 2014. Genetic monitoring of trout movement after culvert 762 remediation: family matters. Can. J. Fish. Aquat. Sci. 71(11): 1680-1694. doi: doi:10.1139/cjfas$763 \quad 2014-0138$. 
765 Nislow, K.H., Hudy, M., Letcher, B.H., and Smith, E.P. 2011. Variation in local abundance and 766 species richness of stream fishes in relation to dispersal barriers: implications for management 767 and conservation. Freshwater Biol. 56(10): 2135-2144. doi: 10.1111/j.1365-2427.2011.02634.x. 768 769 Edited by U.D.o. Transportation. Federal Highway Administration, Washington, DC. p. 272.

771

772 Ombredane, D., Bagliniere, J., and Marchand, F. 1998. The effects of Passive Integrated 773 Transponder tags on survival and growth of juvenile brown trout (\&It;i\&gt;Salmo trutta L.) and 774 their use for studying movement in a small river. Hydrobiologia 371-372(0): 99-106. doi: 775 10.1023/a:1017022026937.

777 Park, D., Sullivan, M., Bayne, E., and Scrimgeour, G. 2008. Landscape-level stream fragmentation 778 caused by hanging culverts along roads in Alberta's boreal forest. Canadian Journal of Forest 779 Research-Revue Canadienne De Recherche Forestiere 38(3): 566-575. doi: 10.1139/x07-179.

Peake, S.J., and Farrell, A.P. 2006. Fatigue is a behavioural response in respirometer-confined smallmouth bass. J. Fish Biol. 68(6): 1742-1755. doi: 10.1111/j.0022-1112.2006.01052.x.

Pépino, M., Rodríguez, M.A., and Magnan, P. 2012. Impacts of highway crossings on density of brook charr in streams. J. Appl. Ecol. 49(2): 395-403. doi: 10.1111/j.1365-2664.2012.02108.x.

787 Perry, R.W., Plumb, J.M., Fielding, S.D., Adams, N.S., and Rondorf, D.W. 2013. Comparing Effects 788 of Transmitters within and among Populations: Application to Swimming Performance of 
789

790

791

792

793

794

795

796

797

798

799

800

801

802

803

804

805

806

807

808

809

810

811 Powers, P.D., Bates, K., Burns, T., Gowen, B., and Whitney, R. 1997. Culvert hydraulics related to

812 upstream juvenile salmon passage. Edited by W.D.o.F.a. Wildlife.

Petty, J.T., Hansbarger, J.L., Huntsman, B.M., and Mazik, P.M. 2012. Brook Trout Movement in Response to Temperature, Flow, and Thermal Refugia within a Complex Appalachian Riverscape. Transactions of the American Fisheries Society 141(4): 1060-1073. doi: 10.1080/00028487.2012.681102.

Peterson, N.P., Simmons, R.K., Cardoso, T., and Light, J.T. 2013. A Probabilistic Model for Assessing Passage Performance of Coastal Cutthroat Trout through Corrugated Metal Culverts. North American Journal of Fisheries Management 33(1): 192-199. doi: 10.1080/02755947.2012.750633.

Poplar-Jeffers, I.O., Petty James, J.T., Anderson, T., Kite, S.J., Strager, M.P., and Fortney, R.H. 2009. Culvert Replacement and Stream Habitat Restoration: Implications from Brook Trout Management in an Appalachian Watershed, U.S.A. Restoration Ecology 17(3): 404-413. doi: 10.1111/j.1526-100X.2008.00396.x.

Powers, P.D., and Orsborn, J.F. 1985. Analysis of Barriers to Upstream Migration: An Investigation of the Physical and Biological Conditions Affecting Fish Passage Success at Culverts and Waterfalls. Albrook Hydraulics Laboratory Washington State University, Pullman, WA. 
814 Richmond, M.C., Deng, Z.Q., Guensch, G.R., Tritico, H., and Pearson, W.H. 2007. Mean flow and 815 turbulence characteristics of a full-scale spiral corrugated culvert with implications for fish 816 passage. Ecological Engineering 30(4): 333-340. doi: 10.1016/j.ecoleng.2007.04.011.

817

818 Rodriguez, M.A. 2002. Restricted movement in stream fish: the paradigm is incomplete, not lost.

819 Ecology 83(1): 1-13.

820

821 Schlosser, I.J. 1991. Stream fish ecology: a landscape perspective. Bioscience 41(10): 704-712.

822

823 Solcz, A.A. 2007. Assessment of culvert passage of Yellowstone cutthroat trout in a Yellowstone

824 river tributary using a passive integrated transponder system, Fish and Wildlife management, 825 Montana State University, Bozeman.

826

827 Torterotot, J.-B., Perrier, C., Bergeron, N.E., and Bernatchez, L. 2014. Influence of Forest Road 828 Culverts and Waterfalls on the Fine-Scale Distribution of Brook Trout Genetic Diversity in a 829 Boreal Watershed. Trans. Am. Fish. Soc. 143(6): 1577-1591. doi: $830 \quad 10.1080 / 00028487.2014 .952449$.

831

832 Tudorache, C., Viaenen, P., Blust, R., and De Boeck, G. 2007. Longer flumes increase critical 833 swimming speeds by increasing burst-glide swimming duration in carp Cyprinus carpio, L. J. Fish 834 Biol. 71(6): 1630-1638. doi: 10.1111/j.1095-8649.2007.01620.x. 
836 Tudorache, C., O'Keefe, R.A., and Benfey, T.J. 2010. The effect of temperature and ammonia 837 exposure on swimming performance of brook charr (Salvelinus fontinalis). Comp. Biochem. 838 Physiol., Part A: Mol. Integr. Physiol.156(4): 523-528. doi: 839 http://dx.doi.org/10.1016/j.cbpa.2010.04.010.

840

841 Videler, J.J. 1993. Fish swimming. Chapman \& Hall, London.

843 Vogel, S. 1994. Life in Moving Fluids: The Physical Biology of Flow. Princeton University Press.

845 Von Karman, T. 1931. Mechanical similitude and turbulence.

847 Wagner, R.L., Makrakis, S., Castro-Santos, T., Makrakis, M.C., Dias, J.H.P., and Belmont, R.F. 848 2012. Passage performance of long-distance upstream migrants at a large dam on the Paraná 849 River and the compounding effects of entry and ascent. Neotropical Ichthyology 10: 785850 795.Available from http://www.scielo.br/scielo.php?script=sci_arttext\&pid=S1679$85162252012000400011 \& n r m=$ iso.

853 Warren, M.L., and Pardew, M.G. 1998. Road crossings as barriers to small-stream fish 854 movement. Trans. Am. Fish. Soc. 127(4): 637-644.Available from <Go to $855|S|>: / / 000075350600011$.

857 Weaver, C.R. 1963. Influence of water velocity upon orientation and performance of adult 858 migrating salmonids. Fisheries Bulletin 63(1): 97-121. 
860 Whiteley, A.R., Coombs, J.A., Hudy, M., Robinson, S.C., Colton, A.R., Nislow, K.H., and Letcher, 861 B.H. 2013. Fragmentation and patch size shape genetic structure of brook trout populations. 862 Can. J. Fish. Aquat. Sci. 70(5): 678-688. doi: doi:10.1139/cjfas-2012-0493.

864 Whiteley, A.R., Coombs, J.A., Letcher, B.H., and Nislow, K.H. 2014. Simulation and empirical 865 analysis of novel sibship-based genetic determination of fish passage. Can. J. Fish. Aquat. Sci. 866 71(11): 1667-1679. doi: doi:10.1139/cjfas-2014-0137.

868 Wofford, J.E.B., Gresswell, R.E., and Banks, M.A. 2005. Influence of Barriers to Movement on 869 Within-Watershed Genetic Variation of Coastal Cutthroat Trout. Ecological Applications 15(2): 870 628-637.Available from http://www.jstor.org/stable/4543380. 
871 (1) Table 1: Study sites characteristics.

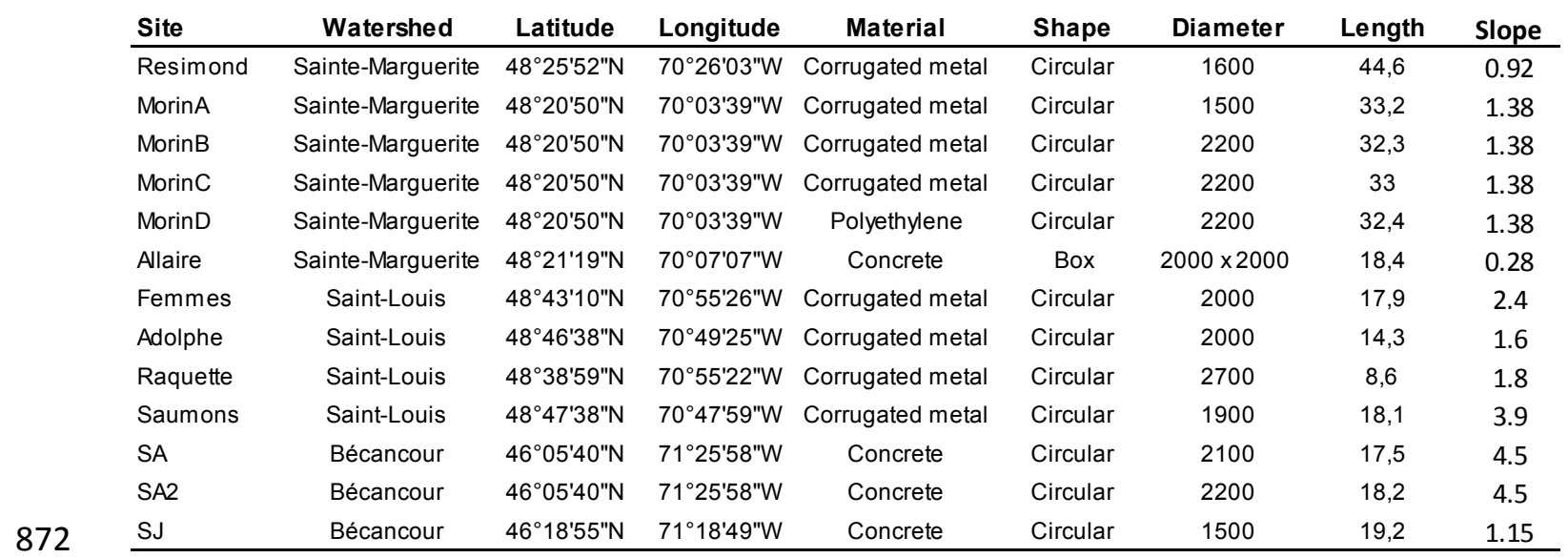

873 *Diameter is in $\mathrm{mm}$, length in $\mathrm{m}$ and slope in \%. 
874 (2) Table 2: Measured range of explanatory variables in their standard units and in body 875 lengths (BL)

\begin{tabular}{lll} 
Conditions & Measured range & Median \\
\hline Fish length (FL) & $85-240 \mathrm{~mm}$ & 126 \\
Mean water temperature & $3.3-18^{\circ} \mathrm{C}$ & 14 \\
Length of culvert & $9-45 \mathrm{~m}$ or $67-360 \mathrm{BL}$ & 19 or 167 \\
Slope of culvert & $0.25-4.5 \%$ & 1.5 \\
Mean flow velocity & $0.4-2 \mathrm{~m} / \mathrm{s}$ or $1.9-23 \mathrm{BL} / \mathrm{s}$ & 0.8 or 6.5 \\
Hydraulic radius & $0.2-0.27$ or $0.1-2.6 \mathrm{BL}$ & 0.09 or 0.6 \\
Depth of dowstream pool & $0.25-1 \mathrm{~m}$ or $1-11.5 \mathrm{BL}$ & 0.6 or 4.5 \\
\hline Trial duration or delay & $24-48 \mathrm{~h}$ & 48 \\
\hline
\end{tabular}


(3) Table 3: Model selection based on the Akaike information criterion (AIC)

\begin{tabular}{|c|c|c|c|c|c|c|}
\hline Model $_{\mathrm{i}}$ & $-2 \log (L)$ & $\mathbf{K}$ & $\mathrm{AlC}_{\mathrm{i}}$ & $\Delta_{\mathrm{i}} \mathrm{AIC}$ & $\Delta_{\mathrm{i}}$ AIC null & $w_{\mathrm{i}}$ \\
\hline Null & 687.49 & 1 & 691.5 & 691.5 & 0.0 & 0.000 \\
\hline$U f+T+T^{2}+P+D+T y p e+R h$ & 415.31 & 8 & 431.31 & 14.3 & 260.2 & 0.001 \\
\hline Uf+S+P+D+Type+Rh & 416.62 & 7 & 430.62 & 13.6 & 260.9 & 0.001 \\
\hline$U f+S+P+D+T y p e+U f^{*} S$ & 416.43 & 7 & 430.43 & 13.4 & 261.1 & 0.001 \\
\hline Uf+Spawn+T+T2+P+D+Type & 404.88 & 8 & 420.88 & 3.9 & 270.6 & 0.127 \\
\hline $\mathrm{Uf}+\mathrm{S}+\mathrm{T}+\mathrm{T}^{2}+\mathrm{P}+\mathrm{D}+\mathrm{Type}$ & 401.03 & 8 & 417.03 & 0.0 & 274.5 & 0.870 \\
\hline
\end{tabular}

879 Table 3: Subset of tested models $(n=208)$ showing the null model and the 5 models with the

880 lowest -2 log-likelihood and AIC values. Explanatory variables are mean water temperature (Tc),

881 mean flow velocity (Uf), hydraulic radius (Rh), depth of downstream pool (P), spawning period

882 (Spawn), culvert type (Type), culvert slope (S), and trial duration (D). K represents the number of

883 parameters in the model, $\Delta_{\mathrm{i}}$ AIC the difference between AIC of model ${ }_{i}$ and AIC of the best

884 model, $\Delta_{i}$ AIC null the difference between the AIC of model ${ }_{i}$ and AIC of the null model and $w_{i}$ the

885 Akaike weight, interpreted as the probability that model $i$ is the best-model given the data. Only

886 one model emerged as providing the best fit to the data. This model, in bold, has an Akaike 887 weigth of 0.87 
(4) Table 4 : Estimation of parameters for the selected model

\begin{tabular}{llrrrr}
\hline & & \multicolumn{3}{c}{ Variables in standard units } \\
& Parameters & ${ }^{*} \boldsymbol{\beta}$ & $\boldsymbol{\beta}$ & \pm SE & OR \\
& & & -4.563 & 4.411 & \\
\hline$\beta 0$ & Intercept & 2.744 & 1.436 & 0.722 & \\
$\beta 1$ & Water temperature & -2.022 & -0.048 & 0.026 & \\
$\beta 2$ & Water temperature & 1.646 & 2.985 & 0.761 & \\
$\beta 3$ & Culvert type (rough v/s smooth) & -0.846 & -1.304 & 0.363 & 0.270 \\
$\beta 4$ & Culvert slope & -0.581 & -2.985 & 0.625 & 0.050 \\
$\beta 5$ & Mean flow velocity & -0.845 & -8.159 & 1.376 & 0.000 \\
$\beta 6$ & Depth of downstream pool & 0.395 & 0.078 & 0.022 & 1.080 \\
$\beta 7$ & Trial duration & 0.869 & -0.012 & 0.005 & \\
$\beta 8$ & Culvert type * fish length & & & & \\
\hline
\end{tabular}

889

Table 4: Standardized estimates $\left({ }^{*} \beta\right)$, estimates $(\beta)$, standard error $(\mathrm{SE})$, chi-square $\mathrm{p}$-values $\left(\mathrm{P}^{*}\right)$

891 and odds ratio (OR) of parameters for the best-fitting model for a dataset with variables in

892 standard units (SI). Odds ratios are computed for main effects with no interactions by

893 exponentiating the estimates. Standardized coefficients are obtained by converting ordinary

894 coefficients $(\beta)$, from which individual probabilities of success can be computed, to standard

895 deviation units. The units are Celsius for temperature, millimeters for fish length, meters per

896 second for flow velocity, \% for culvert slope, meters for depth of downstream pool and hours for

897 trial duration. Culvert type is a categorical variable with rough $=1$ and smooth $=0$. 
(5) Table 5: Validation statistics for the selected model

\begin{tabular}{lcccccc}
\hline & \multicolumn{3}{c}{ Variables in standard units } & \multicolumn{2}{c}{ Variables normalized in BL } \\
Scored dataset & $\mathbf{N}$ & $\boldsymbol{c}$ & Tjur $^{\mathbf{2}}$ & $\boldsymbol{c}$ & Tjur $^{\mathbf{2}}$ \\
\hline Caged fish & 496 & 0.89 & 0.49 & 0.88 & 0.45 \\
Caged fish $=>2^{\text {nd }}$ & antenna & 312 & 0.86 & 0.46 & 0.87 & 0.43 \\
Uncaged fish & 36 & 0.95 & 0.58 & 0.94 & 0.54 \\
Uncaged fish $=>2^{\text {nd }}$ antenna & 21 & 0.89 & 0.5 & 0.9 & 0.45 \\
\hline
\end{tabular}

900 Table 5: $C$ and Tjur's $R^{2}$ statistics evaluating best model's predictive power for 4 datasets, in

901 standards and body lengths units $(B L)$ : caged fish, caged fish that swam $=>2^{\text {nd }}$ antenna, uncaged

902 fish and uncaged fish that swan $=>2^{\text {nd }}$ antenna. A $c$ value between 0.8 and 0.9 means that the

903 model is excellent for predicting outcome while a value $>0.9$ means that the predictive power of

904 the model is outstanding (Hosmer et al. 2013). 
(1) Figure 1

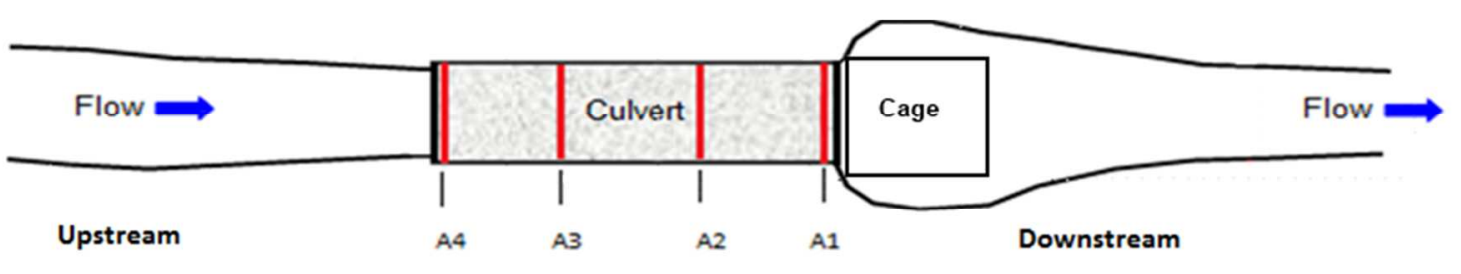

906

907 Figure 1 : Schematic representation of the stationary PIT system installed in culverts, with the 908 cage downstream and the 4 PIT antennas (A1-A4). Adapted from Cahoon et al. (2004) 
909 (2) Figure 2

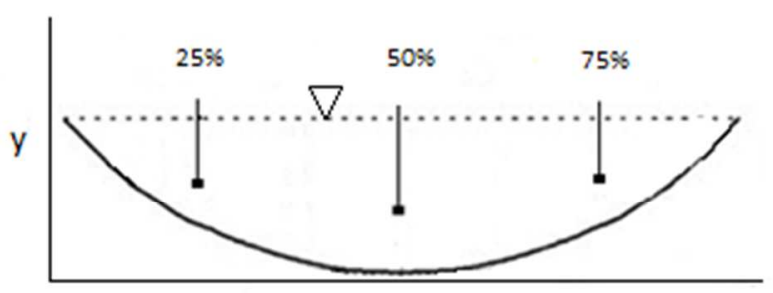

w

910

911 Figure 2: Schematic representation of culvert cross-section with dots representing the location

912 of flow velocity measurements. At 25,50 and $75 \%$ of flow width (w), flow depth (y) was

913 measured, along with mean flow velocity. 
914 (3) Figure 3
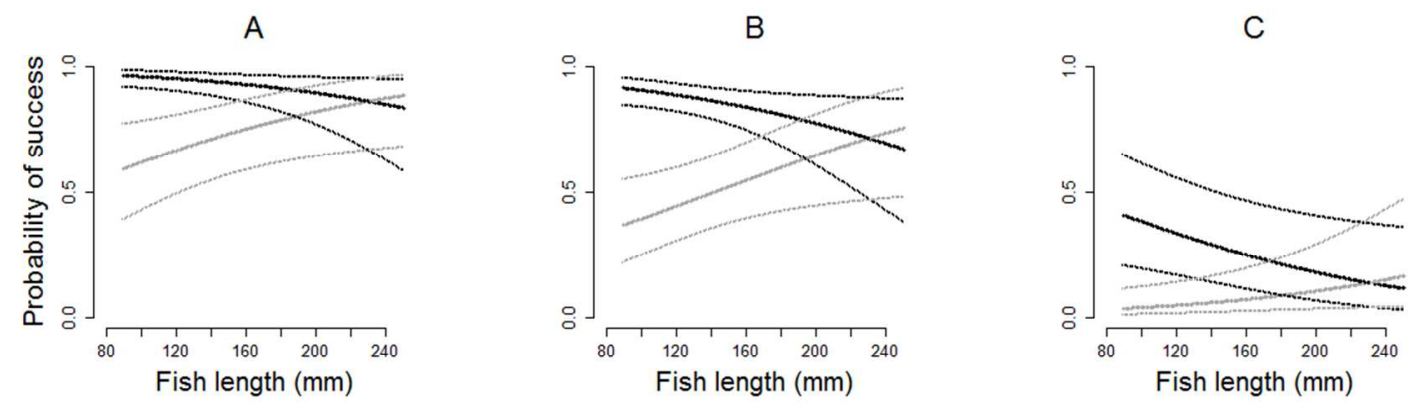

915

916 Figure 2: Panels show the predicted probability and 95\% confidence intervals of success in

917 rough (black line) and smooth (grey line) culverts with regards to fish length for a mean flow

918 velocity of $0.4 \mathrm{~m} / \mathrm{s}(\mathrm{A}), 0.8 \mathrm{~m} / \mathrm{s}(\mathrm{B})$ and $1.7 \mathrm{~m} / \mathrm{s}(\mathrm{C})$, which correspond to the $5^{\text {th }}, 50^{\text {th }}$ and $95^{\text {th }}$

919 percentiles of tested flow velocities. In smooth culvert longer fish had superior passage success,

920 but in rough culverts shorter fish performed better, regardless of the flow velocity. 
921 (4) Figure 4
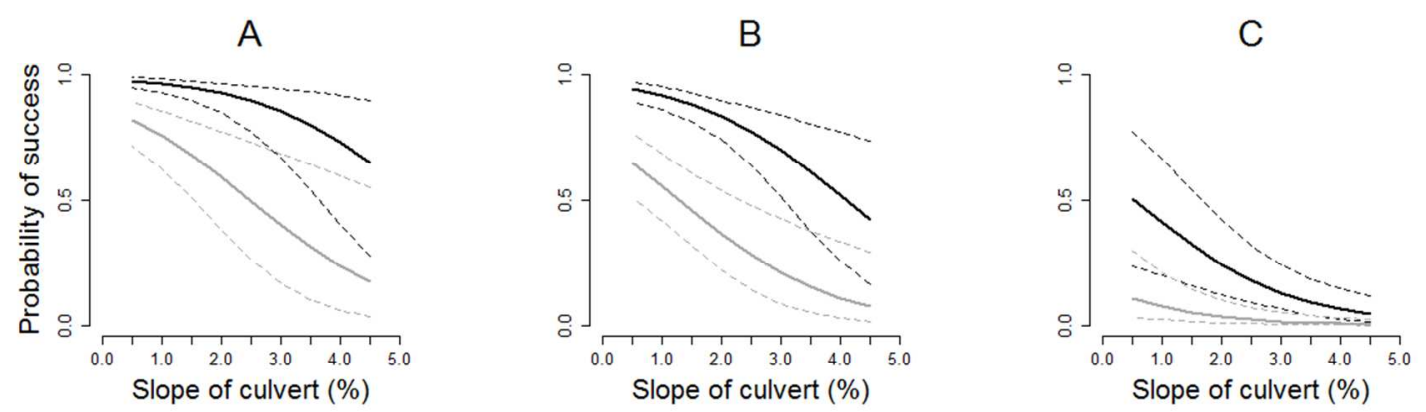

922

923 Figure 3: Panels show the predicted probability and 95\% confidence intervals of success in rough

924 (black line) and smooth (grey line) culverts with regards to culvert slope for a mean flow velocity

925 of $0.4 \mathrm{~m} / \mathrm{s}(A), 0.8 \mathrm{~m} / \mathrm{s}(B)$ and $1.7 \mathrm{~m} / \mathrm{s}(C)$, corresponding to the $5^{\text {th }}, 50^{\text {th }}$ and $95^{\text {th }}$ percentiles of

926 tested flow velocities. Others parameters are set at their mean values (water

927 temperature $=14^{\circ} \mathrm{C}$; flow velocity $=0.8 \mathrm{~m} / \mathrm{s}$; depth of downstream pool $=0.6 \mathrm{~m}$ and fish length $=126$

$928 \mathrm{~mm})$. In general, success decreased with increase of slope. However, it remained higher in rough

929 culverts, regardless of flow velocity conditions. Caution should be applied when interpreting the

930 combinations of slope and velocities. In the current study, the highest velocity was not

931 encountered at the lowest slope and vice versa. More knowledge is needed to better

932 understand the respective effect of slope and velocity on passage. 
933 (5) Figure 5
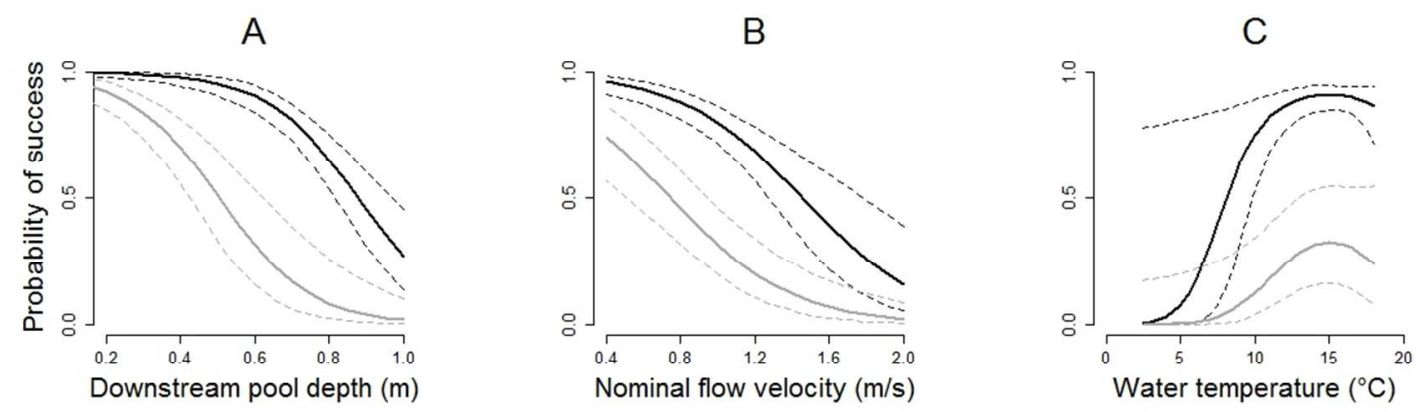

935 Figure 4: Predicted individual probabilities and 95\% confidence intervals of success for fish

936 ascending rough (black lines) and smooth (grey lines) culverts. Panels show the effect of depth

937 of the downstream pool (A), mean flow velocity (B) and trial mean water temperature (C) on the

938 probability of success for a fish of $126 \mathrm{~mm}$, swimming in culverts of $9-45 \mathrm{~m}$ during a $48 \mathrm{~h}$ trial.

939 Others parameters are set at their mean values (water temperature $=14^{\circ} \mathrm{C}$; flow velocity $=0.8$

$940 \mathrm{~m} / \mathrm{s}$; depth of downstream pool=0.6 $\mathrm{m}$ and culvert slope=1.5\%). For each parameter, the

941 probability of success is higher in rough culverts. Passage performance of trout decreases with

942 increasing depth of the downstream pool and flow velocity. Conversely, passage increases with

943 water temperature to an optimum at $15^{\circ} \mathrm{C}$. A limited number of fish (44) were tested at

944 temperature below $7^{\circ} \mathrm{C}$ and panel $\mathrm{C}$ shows a large upper confidence interval for rough culvert.

945 Caution should then be applied when predicting passage at low temperatures. 
$946 \quad$ (6) Figure 6

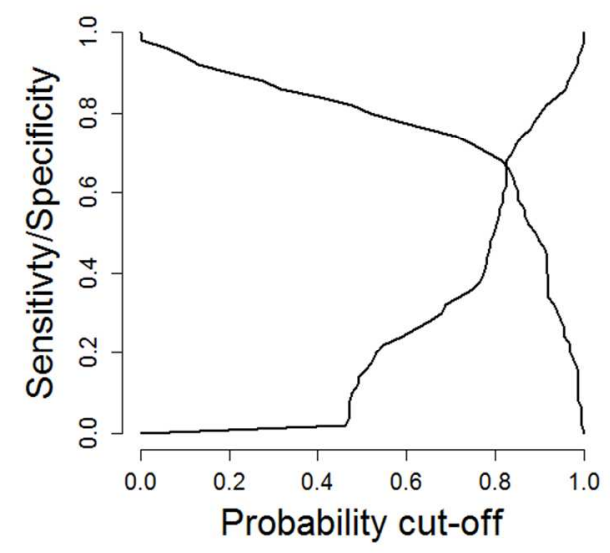

947

948 Figure 6: Sensitivity and specificity under all possible cut-off points. When using the developed

949 model to predict passage success of brook trout in culverts, sensitivity and specificity are both

950 maximized at a probability cut-off of 0.82 . 